\title{
Direito à saúde e políticas públicas: a necessidade de critérios judiciais, a partir dos preceitos constitucionais
}

Têmis Limberger*

\section{Introdução}

Os direitos não são um dado, mas um construído. Pode-se formular essa ideia a partir do pensamento de Hannah Arendt (1998:368-382), que concebe os direitos humanos a partir da construção da igualdade e a cidadania como o direito a ter direitos. O primeiro direito humano é o direito de ter direitos. Isso significa pertencer, pelo vínculo da cidadania, a algum tipo de comunidade juridicamente organizada e viver em uma estrutura em que vigora o princípio da legalidade, evitando-se o surgimento de um novo estado totalitário de natureza. ${ }^{1}$ Dentro dessa perspectiva, quando se comemoram 20 anos da promulgação da Constituição cidadã, a questão principal não é mais a declaração de novos direitos, mas a busca pela efetividade dos mesmos. Aí se insere o direito à saúde que, por ser um direito social, requer a disponibilidade orçamentária para sua implementação. $\mathrm{O}$ direito à saúde teve a sua trajetória de construção nestas duas décadas, mas muito ainda tem de ser feito.

\footnotetext{
* Doutora em direito e mestre pela Universidade Pompeu Fabra, de Barcelona, mestre pela Universidade Federal do Rio Grande do Sul (UFRGS), professora do Programa de Pós-graduação em Direito da Universidade do Vale do Rio dos Sinos (Unisinos). Promotora de justiça no Rio Grande do Sul.

${ }^{1}$ Ver Kohn (2007).
} 
No Brasil, devido à falta de planejamento, são despendidas elevadas quantias quando se trata da implementação dos direitos sociais. Ao invés de haver uma atitude de prevenção, gasta-se muito mais na reparação. Pode-se pensar na questão da educação, moradia, segurança, transporte, trabalho, previdência social, lazer, saúde etc. Todos esses direitos sociais previstos no art. 6ํㅜ caput, da CF, se prestam para investigação, mas devido a um corte metodológico necessário, é imprescindível delimitar a questão. Dentro dessa perspectiva, os dois direitos sociais que têm por parte dos poderes públicos as chamadas "verbas carimbadas", no sentido de que o percentual de recursos já se encontra previamente definido são: educação (art. 212, da CF) e saúde (art. 198, §2º, da CF), daí se constata a importância de investimentos para setores tão prioritários, para que o Brasil seja, no futuro, um país sem tantas desigualdades sociais. A relação que se pode estabelecer entre esses dois direitos sociais é: educação e saúde, no sentido de que quanto maior o nível de instrução, mais saudável é a população. Estudos² demonstram que a educação é uma ferramenta importante, ao se mencionar algumas problemáticas, tais como: mortalidade infantil, gravidez precoce e número de filhos por núcleo familiar.

Este artigo aborda o direito à saúde, especialmente nestes últimos anos da recente história constitucional democrática brasileira. O desafio que se impõe é como fazer com que o direito à saúde não seja um comando meramente programático e se torne efetivo.

Diante desse quadro, impõe-se a seguinte questão: quais as possibilidades e limites do controle judicial, atinente às políticas públicas que visem à implementação do direito à saúde?

Para responder a essa questão, alguns posicionamentos são necessários: por que vigora (ou) no direito administrativo brasileiro o dogma da impossibilidade de revisão dos atos administrativos, que se albergavam sob o manto da discricionariedade administrativa; qual o conceito de política pública; quais os critérios para se estabelecer a intervenção do Poder Judiciário nessa seara.

$\mathrm{O}$ artigo propõe uma abordagem das políticas públicas como determinações constitucionais, ou seja, mandatos a serem realizados pelo administrador, sujeitos, portanto, ao controle judicial. Assim, tarefas que são previstas na Constituição e que devem ser realizadas de acordo com a capacidade orçamentária, mas não são

\footnotetext{
${ }^{2}$ Scliar (2002:95) escreve: “(...) Sabe-se que a morbimortalidade materna, por exemplo, correlaciona-se inversamente com o grau de educação formal, independente das condições socioeconômicas. Para que o processo educativo em saúde atinja a plenitude de seus objetivos é preciso percorrer várias etapas: a partir de um diálogo com a população, procura-se informar as pessoas, para que, informadas, adotem uma atitude positiva, que deve gerar um comportamento; esse comportamento, idealmente, deveria ser introjetado sob a forma de hábito, ou seja, comportamento automatizado. Disseminado, o hábito evolui para o costume, que é uma prática generalizada, incorporada à própria cultura" (grifo do autor). Ver também Szwarcwald (1997).
} 
consideradas uma discricionariedade administrativa, não ficam, portanto, imunes a questionamento judicial. Pretende-se, então, revisar o conceito de discricionariedade da administração, que foi transposto equivocadamente do direito francês para o direito brasileiro, e também a forma de realização dos direitos sociais, em que a doutrina alemã não se adapta totalmente à realidade brasileira. Por isso, a necessidade de se desenvolver uma teoria voltada às especificidades de nosso país, desde a ótica de uma hermenêutica comprometida com uma nova crítica do direito até a busca de uma solução adequada constitucionalmente.

O direito administrativo é o direito constitucional concretizado, em uma síntese formulada pela doutrina alemã. $\mathrm{O}$ administrador, na realização das políticas públicas, deve observar os preceitos constitucionais. $\mathrm{O}$ mandato político não deve ser desempenhado conforme critérios subjetivos do governante, mas representar políticas públicas a serem desenvolvidas em conformidade com os ditames constitucionais. Direitos sociais importantes foram consagrados no art. 6o da CF, visando à execução pelo administrador. Porém, tais preceitos não têm sido cumpridos, opera-se uma situação de crise, pois o Estado brasileiro não foi capaz de atender às demandas do liberalismo clássico, com os direitos de cunho individual e tampouco conseguiu realizar as demandas do Estado social. O Estado imiscuiu-se em atividades que não eram próprias do poder público e deixou de realizar atividades que eram prioritárias. Atualmente, não se afigura um projeto político claro com realização às demandas prestacionais sociais. Como consequência, os serviços públicos não são prestados ou o são de forma deficiente.

Assim, no Brasil, os direitos sociais para que sejam efetivos demandam um caminho diferente dos países europeus, onde estes são uma determinação da Constituição ao legislador ordinário ou ao administrador. Em nosso país, diante da particularidade própria em que esses comandos não são atendidos por seus destinatários, é importante a intervenção do Poder Judiciário. O desafio ocorre no sentido de verificar os limites em que ocorre a atuação do Poder Judiciário, que não pode substituir, em atividades, os outros dois poderes, mas tem que propiciar a efetividade dos direitos fundamentais sociais, quando decorrentes de políticas públicas insuficientes ou inexistentes.

A realização dos direitos sociais é de suma importância, principalmente em países de modernidade tardia, ${ }^{3}$ como o Brasil. Na época em que foi realizada a Constituinte, vivia-se uma euforia como se a partir da colocação das garantias na Constituição fosse haver uma transformação em nossa realidade. Pairava na so-

\footnotetext{
${ }^{3}$ Para Streck (2004): “o que houve (há) é um simulacro de modernidade. (...) Ou seja, em nosso país as promessas de modernidade ainda não se realizaram. E, já que tais promessas não se realizaram, a solução que o establishment apresenta, por paradoxal que possa parecer, é o retorno ao Estado (neo)liberal. Daí que a pós-modernidade é vista com a visão neoliberal. Só que existe um imenso déficit social em nosso país e, por isso, temos que defender as instituições da modernidade contra esse neoliberalismo pós-moderno".
} 
ciedade a ideia de pensamento mágico, como se da previsão na Constituição fosse advir uma modificação na situação fática. É claro que a garantia representa um compromisso importante em termos de desenvolvimento de políticas públicas, isto é, o país que queremos ser no terceiro milênio.

Passaram-se quase 20 anos para que começasse a se amadurecer no sentido de que os direitos sociais fossem relacionados com os dispositivos orçamentários. É o que Canotilho e Moreira (1991) denominam de "Constituição orçamental". ${ }^{4}$ As medidas de gestão orçamentária são importantes quando se pretende a realização dos serviços públicos.

Questões vitais como saúde, educação, segurança e moradia reclamam para sua implementação dispêndios por parte do poder público, que precisa contar com disposições orçamentárias. Logo, o administrador quando concretiza uma política pública encontra no orçamento o limite objetivo da reserva do possível. Da mesma forma, diante da omissão ou precariedade da implementação da política pública, o Poder Judiciário fica adstrito ao orçamento, mas pode pronunciar-se quando provocado, para efetivar os direitos sociais. Durante muitos anos havia a errônea concepção de discricionariedade administrativa que servia para agasalhar todos os desmandos ou ineficácia do Executivo. Sob o manto do ato discricionário não poderia o Judiciário se imiscuir na atividade da administração. As ações judiciais interpostas e algumas decisões judiciais indicam que houve uma mudança de posição, é claro que isso não significa suprimir ou substituir a atividade administrativa, mas buscar a efetividade dos direitos sociais.

Da análise das decisões jurisprudenciais proferidas pelo Supremo Tribunal Federal (preponderantemente) em matéria de políticas públicas, especialmente as que visam à implementação do direito social à saúde é que se terá um perfil dos limites e critérios de atuação do Poder Judiciário, tomando-se como referência a promulgação da atual Constituição Federal. Desse modo, será utilizado aqui o pensamento de Hannah Arendt, partindo-se da ideia de que os direitos não são um dado, mas um construído, neste aspecto o direito à saúde representa um marco importante de desenvolvimento, no sentido de que sua evolução vem sendo construída pelos operadores do direito, para promover condição de dignidade para o cidadão. Outro referencial teórico é o desenvolvimento de uma dogmática da interpretação constitucional, baseada em novos métodos hermenêuticos ${ }^{5}$ e na sistematização de princípios específicos de interpretação constitucional.

\footnotetext{
${ }^{4} \mathrm{Na}$ Constituição orçamental estariam os preceitos relativos ao orçamento do Estado, principalmente a aprovação parlamentar do orçamento, incluindo a autorização parlamentar anual dos impostos e a autorização e controle parlamentar das despesas públicas.

${ }^{5}$ Diz Streck (2004:847): “A hermenêutica entendida a partir de uma nova crítica do direito, (...) calcada na matriz ontológico-fundamental (fenomenologia hermenêutica), tem a função de construir as condições de possibilidade para a compreensão do problema relacionado à jurisdição constitucional, naquilo que lhe é mais caro e precioso, isto é, o acesso à justiça e a efetividade do sistema jurídico".
} 
Com esses balizadores será possível travar uma discussão da eficácia e limites de implementação das políticas públicas de concretização dos direitos sociais, quando são submetidas ao crivo do Poder Judiciário, especialmente no que diz respeito ao direito à saúde, não no sentido de sentenças formuladas com critérios eminentemente subjetivos, mas a decisão adequada, desde o ponto de vista constitucional.

\section{O dogma da impossibilidade de revisão judicial dos atos da administração, sob o manto da discricionariedade administrativa}

Durante muitos anos, no direito brasileiro vigorava o entendimento da impossibilidade de revisão judicial da atividade administrativa. O controle judicial dos atos da administração não era realizado, fundado na justificativa da discricionariedade administrativa. Essa posição que vigorou em nosso país de forma inconteste ainda encontra seguidores, embora se encontre superada, por no mínimo, três motivos: a impossibilidade de revisão dos atos administrativos por parte do Judiciário, que é doutrina transposta do direito francês, em que existe uma especificidade que é o contencioso administrativo, que no direito brasileiro não encontra similar. O segundo motivo reside na teoria transposta do direito alemão em que os direitos sociais são comandos endereçados ao Legislativo e administrativo, não cabendo ao Judiciário esse controle. Ocorre que naquele país tais poderes realmente levam a sério a implementação dessas políticas públicas, sem que a interferência do Judiciário seja necessária. O terceiro aspecto a ser considerado é que, no Estado democrático de direito, somente existe escolha do administrador vinculada aos preceitos constitucionais, em especial pela pauta dos direitos fundamentais. O Poder Judiciário quando efetua essa decisão não pode cair na casuística, autorizando ou negando todas as pretensões que lhe vêm a julgamento, sem considerar os dispositivos orçamentários, mas deve buscar a solução adequada constitucionalmente, e aí reside a questão.

Com essa perspectiva, este artigo pretende investigar os limites em que são controladas as políticas públicas judicialmente. Logo, o questionamento judicial dos atos da administração tem ocorrido, mas o importante é apontar os critérios de como ele vem sendo implementado, para que o Judiciário não substitua o administrador e tampouco o administrador fique livre dos controles judiciais. Essa sindicabilidade tem de ocorrer de forma a concretizar os preceitos estabelecidos pela Constituição Federal. As grandes questões do direito público neste terceiro milênio dizem respeito à possibilidade de controle judicial dos atos da administração referente às políticas públicas. 
Em um país como o Brasil, em que os direitos sociais ainda não estão assegurados para grande parte da população, a pergunta que se faz é a seguinte: fica à vontade a implementação das políticas públicas por parte do Executivo ou o Poder Judiciário pode ser um importante mecanismo de pressão, na implementação desses direitos e em que limites? Assim, a título de exemplo, referente ao direito à saúde, a Constituição objetiva assegurar: um tratamento caro no exterior para uma só pessoa ou o tratamento de doença epidemiológica relevante para uma parcela expressiva da sociedade? Por isso, quando está ausente ou insuficiente uma política pública, o Judiciário deve agir, mas com critérios e limites, sob pena de se cair no subjetivismo judicial. Daí advém a necessidade da investigação, pois em casos de omissão ou atuação precária do administrador, por vezes o Judiciário manifesta-se de forma tímida ou sem critérios. Com este artigo, pretende-se contribuir para tal questão, no sentido de apontar critérios formulados a partir dos preceitos constitucionais, sem que se caia em um casuísmo destituído de fundamento legal.

Com relação ao primeiro aspecto, a inadequação do modelo francês transposto à realidade brasileira, faz-se um retrospecto a respeito dos controles da administração. Pode-se afirmar que existem dois sistemas: o da unidade e o da dualidade da jurisdição. O sistema da unidade ou da dualidade da jurisdição decorre da interpretação do princípio da separação dos poderes. É importante salientar que a doutrina a que se convencionou a denominação "separação dos poderes" não foi assim conceituada por seu autor, Montesquieu (1979:148-154). Da leitura de sua obra, extraem-se duas ideias principais, quais sejam: a distinção tripartite das funções do Estado e a ideia de controle recíproco entre tais atividades. Em momento algum escreveu o autor a palavra "separação dos poderes", isso decorreu da interpretação principal de sua obra, mormente a apropriação da doutrina que se constituiu em um dos paradigmas apregoados pela Revolução Francesa. A interpretação e crítica de Louis Althusser não tiveram fortes ecos, no sentido de que Montesquieu era de origem nobre, conhecido como barão de La Brède e formulou a teoria apenas para fortalecer o poder monárquico, na época em que este se encontrava em crise.

Na França, berço do princípio da separação dos poderes devido à doutrina de Montesquieu, este foi interpretado de forma drástica como a impossibilidade de um poder exercer o controle sobre outro. A origem histórica dessa interpretação encontra-se na desconfiança que os legisladores da Revolução Francesa tinham para com o Poder Judiciário, pois este tinha se mostrado resistente às conquistas populares. Waline (1952:45) assevera que a Lei no 16, de 24 de agosto de 1790, dispunha sobre a organização judiciária e proclamava a separação das funções administrativas e judiciais, que foi reafirmada com o período que se seguiu à Revolução Francesa. Houve proibição legal expressa aos juízes do conhecimento da matéria 
administrativa. As reclamações com conteúdo administrativo não poderiam ser, em nenhum dos casos, encaminhadas aos tribunais. Deveriam ser submetidas ao rei, então chefe da administração geral.

Por contencioso administrativo, entende-se o conjunto de regras relativas aos litígios organizados que questionam a atividade dos administradores públicos. $\mathrm{O}$ progresso do direito administrativo francês deveu-se à existência de um contencioso. Essa instituição garantiu o desenvolvimento do direito propriamente dito, por meio das garantias de legalidade criadas, pela importância do aspecto moral da conduta dos administradores, dando respaldo às teorias subjetivas.

O recurso por excesso de poder é uma criação jurisprudencial devido ao próprio Conselho de Estado, constituindo-se o principal instrumento de controle da legalidade administrativa. ${ }^{6} \mathrm{O}$ Conselho de Estado ${ }^{7}$ é um órgão de fiscalização dos atos da administração, situado dentro do próprio Executivo e que desempenha suas funções decisórias com imparcialidade e em consonância com a legalidade. A justificativa é no sentido de que o Legislativo é o poder constituído a partir da vontade popular e não seria democrático a substituição da representação da soberania do povo pelo Poder Judiciário, que não é eleito democraticamente.

Esta questão é bem enfrentada por Sérgio Cademartori (2006), que analisa a questão da legitimidade. Assim, o Poder Legislativo e o Poder Judiciário possuem intervenção, calcados em pressupostos de legitimidade distintos. A legitimidade do Poder Legislativo vem da ideia de soberania popular. O Poder Legislativo é o representante da população, e podem ser feitas críticas ao modelo representativo. ${ }^{8}$ Com pressuposto diferente de legitimidade se encontra o Poder Judiciário, que possui seu fundamento no Estado de direito.

Basicamente, são essas as razões de ordem histórica pelas quais não se permite a revisão dos atos administrativos no direito francês, que consagra a dualidade de jurisdição. Tal doutrina é inaplicável ao direito brasileiro em virtude do art. 5ㅜ, $X X X V$, da CF, que consagra a inafastabilidade do controle judicial de todos os atos. Logo, os atos da administração que traduzem opções de políticas públicas não podem ficar à margem do questionamento judicial, o desafio está em estabelecer esses critérios.

\footnotetext{
${ }^{6}$ Laubadère (1995), a respeito da evolução do recurso de excesso de poder, faz uma análise de sua evolução até o final do século XX.

${ }^{7}$ Da mesma forma, o Conselho Constitucional é o órgão a quem incumbe o controle da constitucionalidade das leis, que é realizado de uma maneira preventiva, não se permitindo ao Judiciário o controle destas questões.

${ }^{8}$ A respeito das insuficiências do modelo representativo e o movimento que ocorre em prol da democracia participativa, não se tratará desta questão, por não ser objeto deste artigo.
} 


\section{Direitos sociais no Brasil e em países que realizaram o Estado social - trajetórias distintas}

O segundo motivo de análise é o das especificidades do modelo alemão que foram equivocadamente transpostas para o Brasil, sem as necessárias adequações. Assim, no dizer de Hesse (1996:98):

derechos sociales fundamentales como por ejemplo (...) el derecho a una vivienda adecuada (...) no se hacen ya efectivos por el hecho de que se respeten y amparen, sino que requieren de antemano, y em cualquier caso más que en los derechos fundamentales tradicionales, acciones del Estado tendentes a realizar el programa contenido en ellos. No sólo exige esto regularmente un actuar del legislador, sino también el de la Administración; y puede afectar a

los derechos-libertad ajenos. Por ello, los derechos fundamentales no alcanzan a justificar pretensiones de los ciudadanos invocables judicialmente en forma directa, como cuadraría a la doctrina de los derechos fundamentales.

É claro que os direitos sociais têm uma estrutura distinta dos direitos individuais, do liberalismo clássico. São comandos voltados prioritariamente para o administrador e legislador, e para a sua implementação dependem de possibilidade orçamentária. Porém, no contexto brasileiro, diante da inoperabilidade desses poderes, por vezes o Judiciário representa um fator importante para pressionar a realização das políticas públicas, visando assegurar a dignidade da pessoa humana, composto pelo mínimo existencial. Um exemplo que pode ser apontado é o tratamento da Aids em nosso país. Diante da inicial omissão dos poderes Legislativo e Executivo, no sentido de promover políticas públicas, no tocante à prevenção e tratamento do HIV, ações reiteradas no âmbito judicial, pedindo medicamentos, incentivaram o Brasil para que se tornasse um país referência na área.

Assim, apropriadas as considerações de Andreas Krell (2002:109), conhecedor das realidades alemã e brasileira:

Em face dos problemas sociais candentes de um país periférico como o Brasil, o princípio tradicional da separação dos poderes deve ser entendido sob os parâmetros e dimensões novas e diferentes dos das nações centrais. Ainda não foram aproveitadas as potencialidades dos modernos instrumentos processuais do direito brasileiro para correição judicial das omissões dos poderes Executivo e Legislativo na área das políticas públicas, como a ação civil pública e a ação de inconstitucionalidade por omissão. 
Em alguns países, como a França e a Alemanha, em que o Estado providência cumpriu seu papel, assegurando os direitos sociais à população, é adequado que se discuta a permanência ou a diminuição de algumas garantias, devido à proporção robusta que estas alcançaram. Diferentemente, no Brasil, em que a população não conseguiu atingir níveis homogêneos em termos de acesso aos direitos sociais.

A "reserva do possível" 9 tem sido outro conceito mal transposto ao direito comparado. Essa teoria é adaptação de uma expressão cunhada no direito alemão, que entende que a construção de direitos subjetivos à prestação material de serviços públicos pelo Estado está sujeita à condição da disponibilidade dos respectivos recursos, ou seja, no campo orçamentário.

Assim, é necessário para avaliar em que limites está ocorrendo o provimento judicial a respeito das políticas públicas, em um país como o Brasil, com especificidades próprias, principalmente no que diz respeito às grandes desigualdades econômicas e culturais. É perigoso importar diretamente conceitos cunhados em outros países com contexto cultural e socioeconômico diferentes. O Brasil, que é um país em desenvolvimento, não pode transportar diretamente teorias de países ricos. $\mathrm{O}$ debate europeu sobre a redução dos direitos conquistados durante o Estado social não pode ser transferido, porque o Estado providência nunca foi efetivado plenamente.

Ainda, concernente à eficácia, é importante a posição de Ingo Sarlet (2007:297), que posiciona os direitos de cunho prestacional como autênticos direitos fundamentais constituindo-se, por isso, direito imediatamente aplicável, nos termos do art. 5은 $\S 1^{\circ}$, da CF. Por isso, no embate entre o Estado social intervencionista e altamente regulador e a nefasta tentativa de implementar um Estado minimalista desenhado a partir da globalização e da ideologia neoliberal, o correto manejo da proibição de retrocesso na esfera dos direitos fundamentais sociais poderá se constituir uma ferramenta útil para a construção do perfil do Estado brasileiro, com dignidade para cada indivíduo e, portanto, uma vida saudável para todos os integrantes do corpo social.

Este artigo aborda a importância dos poderes Executivo e Legislativo na implementação de políticas públicas e o papel do Judiciário na busca de efetividade do direito social à saúde, fixando os seus limites e possibilidades de atuação.

\footnotetext{
${ }^{9}$ Segundo o Tribunal Constitucional Federal da Alemanha, esses direitos a prestações positivas “estão sujeitos à reserva do possível no sentido daquilo que o indivíduo, de maneira racional, pode esperar da sociedade". Essa teoria impossibilita exigências acima de um limite básico social; a Corte recusou a tese de que o Estado seria obrigado a criar quantidade suficiente de vagas nas universidades públicas para atender a todos os candidatos (Krell, 2002).
} 


\section{O controle judicial e sua perspectiva constitucional}

No Brasil, os poderes Executivo e Legislativo não têm implementado as políticas públicas a contento, por isso a discussão se insere na órbita judicial. Nesse contexto, outro aspecto a ser considerado é a sindicabilidade das políticas públicas como decorrência do Estado democrático de direito. Atualmente não existe um poder discricionário livre, mas somente um poder discricionário vinculado. Vinculação esta que se pode relacionar aos ditames constitucionais. Logo, o conteúdo das políticas públicas não pode ficar à vontade do administrador, mas tem de buscar efetivar os preceitos contidos na Constituição.

O direito administrativo se estruturou no século XIX, a partir do princípio da legalidade, este foi o primeiro grande freio que foi imposto ao administrador, porém, atualmente com a denominada fuga do direito administrativo ou a tendência neoliberalizante do Estado, ocasionando a chamada eficácia com relação a terceiros "drittwirkung", ${ }^{10}$ novos pressupostos devem ser erigidos. Para García de Enterría (2007:147), o aspecto subjetivo da justiça administrativa, que rompeu o mito histórico de sua suposta objetividade, atrás da qual se escondia uma superioridade formal da administração sobre o cidadão, considerado ainda súdito, que deveria ceder ante a suposta superioridade dos "interesses gerais", é uma conquista irrenunciável do nosso tempo.

Por isso, o grande desafio que é posto aos estudiosos do direito administrativo na atualidade é a possibilidade de controle judicial. Afirma Moreira Neto (2006:406) $)^{11}$ que há atuações administrativas constitucionalmente mandatórias, como é o caso das políticas públicas nacionais e não apenas governamentais, da educação, da saúde e da segurança pública. Assim, o Estado democrático de direito reclama a implementação dos direitos fundamentais, por meio das políticas públicas. Desse modo, a atividade administrativa no terceiro milênio deve ser pautada dentro dos balizadores que compõem o Estado democrático de direito: os direitos do homem e a democracia substantiva. A partir desses dois vetores são estatuídos os quatro paradigmas atuais do direito administrativo: legitimidade, finalidade, eficiência e resultados. Devem ser analisados de forma conjunta e não isoladamente, tendo em vista a realização do serviço público. Esses critérios serão necessários quando são exercidos os controles com relação à atividade administrativa, quer no âmbito preventivo ou repressivo.

\footnotetext{
${ }^{10}$ Os conflitos não mais se situam na polaridade Estado x cidadão, mas nas relações grupo x indivíduo. Isso ocorre porque alguns grupos econômicos possuem poder paralelo ao Estado, decorrente, em alguns casos, das privatizações, em que muitos serviços públicos são prestados por empresas privadas. O desenvolvimento da dtittwirkung, também conhecida por eficácia diante de terceiros ou eficácia horizontal, é hoje questão principal nos direitos do indivíduo. Os litígios foram se deslocando do plano das relações públicas para o das privadas. A propósito, ver Bilbao Ubillos (1997:256).

${ }^{11}$ Ver também Alli Aranguren (2004:377).
} 
Assim legitimidade e finalidade, que eram requisitos intrínsecos aos atos administrativos, demandam um novo olhar. No tocante à legitimidade serão constitucionais as prestações públicas que respeitem os direitos fundamentais. Não basta mais somente a legitimidade fundada no que se denominava pacto social, mas deve-se perquirir a respeito do atendimento dos valores que visam implementar a pauta dos direitos humanos, principalmente quando estes completam 60 anos. Assim a legitimação é, sobretudo, um fenômeno antropológico indissociável do consenso alcançado pelos grupos sociais, que consiste na verificação da concordância com os fenômenos políticos e valorativos relacionados ao poder, ou seja, à sua concentração, à sua distribuição, ao seu acesso, ao seu exercício e ao seu controle. Concernente à finalidade, estamos sob a época da redescoberta dos valores e das finalidades, deve-se buscar identificar a finalidade nos princípios.

A eficiência é um princípio trazido pela EC no 19/1998, que traduz um aspecto axiológico, no sentido de que o direito administrativo deve e pode ser um instrumento para a realização dos direitos fundamentais e facilitador do desenvolvimento econômico e social.

Após o aspecto valorativo ocorre o último paradigma, que é o do resultado. Cuida-se de mensurador prático, em que são buscadas técnicas de controle da gestão. ${ }^{12}$ Deve-se atentar para a prestação do serviço público, que possui um espectro distinto do privado. Já foi mencionado o fenômeno da eficácia horizontal dos direitos fundamentais, onde os conflitos migraram da seara pública à privada. É a denominada fuga do direito administrativo em direção ao direito privado. Isso aconteceu com a questão da saúde também. Há, porém, especificidades próprias, pois a iniciativa privada somente se interessa por setores em que há a possibilidade de lucro. As áreas deficitárias são suportadas pelo poder público. Assim, a prestação de serviço pelo SUS responde por aproximadamente $75 \%$ da população brasileira. ${ }^{13}$ Isso demonstra que os $25 \%$ restantes pertencem à iniciativa privada, porque são setores com a potencialidade de lucro. Assim, o

\footnotetext{
12 São apresentadas técnicas destinadas a realizar as seguintes funções: a) a definição de objetivos de políticas públicas; b) a identificação das estruturas administrativas responsáveis por sua consecução; c) definição das normas de desempenho que traduzam um compromisso quanto ao grau de realização dos objetivos demarcados em função dos meios a eles destinados; d) os resultados comensurados e sua comunicação; e) outorga de facilidades de gestão aos responsáveis proporcionalmente a seu desempenho (conforme convênios de gestão); f) análise dos dados de desempenho integrados com vista a informar as subsequentes decisões sobre recursos e orçamento; g) fixação de acompanhamentos físicos e contábeis necessários para os controles, correntes e posteriores (Moreira Neto, 2008:139).

${ }^{13}$ De acordo com a pesquisa mundial sobre saúde, desenvolvida pela OMS e coordenada no país pelo Centro de Informação Científica e Tecnológica (CICT) da Fiocruz, em estudo que avalia os sistemas de saúde de 71 nações, consigna que os brasileiros dispensam em média 19\% da renda familiar com saúde, da parcela da população de $25,8 \%$ que têm acesso aos planos de saúde privados, enquanto a maioria 74,2\% conta com os serviços do Sistema Único de Saúde (SUS). Disponível em: <www. ministeriodasaude.gov.br>. Acesso em: 20 ago. 2008.
} 
princípio da eficiência deve ser aferido com características próprias e não com os mesmos balizadores privados.

\section{Conceito de política pública, desde o prisma jurídico, com ênfase no direito à saúde}

O conceito de política pública partiu da ciência política e da administração pública, mas hoje encontra importante espaço de reflexão no campo jurídico. Logo, a definição apresentada na ciência política é a dimensão normativa ou moral do Estado, que perpassa a filosofia política ocidental e objetiva garantir uma vida feliz ao cidadão. A questão da política pública apresenta um núcleo com interseção na organização do sistema internacional, de organização na sociedade e da organização do Estado. Não se apresenta como algo isolado, mas que deve dialogar tendo em conta os três vértices: internacional, estatal e social.

Assim, já se percebe por que o tema das políticas públicas entra na pauta jurídica, nos últimos tempos. Da passagem do Estado liberal com sua feição de abstenção, ${ }^{14}$ chega-se ao Estado social com seu conteúdo de intervenção, a partir das demandas concretas formuladas pelo cidadão. É o constitucionalismo social inaugurado no início do século XX, depois da Revolução Industrial e do Socialismo, que tem sua marca na Constituição mexicana de 1917, Constituição de Weimar de 1919 e, em nosso país, na Constituição de 1934, da Era Vargas. Passado o movimento pendular no sentido de constituições antidemocráticas e democráticas, chega-se à Constituição de 1988, em que a democracia começa a se estabilizar e confere margem para a efetividade dos direitos. Assim, a discussão das políticas públicas ganha espaço no cenário jurídico.

Um delineamento a respeito do tema das políticas públicas é trazido por Bucci (2006:31), como programas de ação destinados a realizar, sejam os direitos a prestações, diretamente, sejam a organizações, normas e procedimentos necessários para tanto. As políticas públicas não são, portanto, categoria definida e instituída pelo direito, mas arranjos complexos, típicos da atividade político-administrativa, que a ciência do direito deve estar apta a descrever, compreender e analisar, de modo a integrar a atividade política, os valores e os métodos próprios do universo jurídico.

Uma questão que surge é no sentido de delimitar quais as ações que conduzem à implementação das políticas públicas, considerando-se as de cunho individual e coletivo. Estas últimas não suscitam dúvidas. A indagação diz respeito às

\footnotetext{
${ }^{14}$ A propósito a Constituição dos Estados Unidos de 1787 e a Constituição francesa de 1791.
} 
ações individuais, prestam-se elas para estatuir políticas públicas? É sabido que o art. 5o, XXXV, CF, consagra o acesso à justiça de forma ampla e irrestrita. Assim, não se pode impedir o acesso, mas a concessão de medicamentos não previstos como essenciais demanda uma atenção para a sua decisão. O art. 196 da CF conjuga o direito à saúde, a políticas sociais e econômicas, para que seja possível assegurar a universalidade das prestações e preservar a autonomia dos cidadãos, independente do acesso maior ou menor do Poder Judiciário. Segundo Barroso: "presume-se que Legislativo e Executivo, ao elaborarem as listas referidas, avaliaram, em primeiro lugar, as necessidades prioritárias a serem supridas e os recursos disponíveis, (...)".

Esse pressuposto é corolário de um argumento democrático. Os recursos obtidos para o fornecimento dos medicamentos são obtidos pelos tributos suportados pela população. Dessa forma, os representantes eleitos pelo processo democrático devem estabelecer quais são as prioridades na atual conjuntura. Pode ser simpático o argumento de ampla concessão de qualquer medicamento, porém isso é falacioso, pois os recursos orçamentários são limitados em qualquer país, não é possível pretender fazer tudo a qualquer gasto. $\mathrm{O}$ argumento de que os recursos públicos são mal utilizados e, por vezes, desviados, não é cabível nessa discussão, embora seja necessária a devida responsabilização na órbita da improbidade administrativa. Como os recursos são limitados não se pode pretender o pagamento de um medicamento, por vezes com valor altíssimo, não testado suficientemente, em prol de uma lista estatuída a partir dos critérios legais e de implementação do Executivo.

Por isso é importante a decisão proferida pela ministra Ellen Gracie na SS 3073/RN ${ }^{15}$ que considerou inadequado fornecer medicamento que não constava da

\footnotetext{
${ }^{15}$ STF, DJU 14.2.2007, SS 3073/ RN, rel. ministra Ellen Gracie. Verifico estar devidamente configurada a lesão à ordem pública, considerada em termos de ordem administrativa, porquanto a execução de decisões como a ora impugnada afeta o já abalado sistema público de saúde. Com efeito, a gestão da política nacional de saúde, que é feita de forma regionalizada, busca uma maior racionalização entre o custo e o benefício dos tratamentos que devem ser fornecidos gratuitamente, a fim de atingir o maior número possível de beneficiários. Entendo que a norma do art. 196 da Constituição da República, que assegura o direito à saúde, refere-se, em princípio, à efetivação de políticas públicas que alcancem a população como um todo, assegurando-lhe acesso universal e igualitário, e não a situações individualizadas. A responsabilidade do Estado em fornecer os recursos necessários à reabilitação da saúde de seus cidadãos não pode vir a inviabilizar o sistema público de saúde. No presente caso, ao se deferir o custeio do medicamento em questão em prol do impetrante, está-se diminuindo a possibilidade de serem oferecidos serviços de saúde básicos ao restante da coletividade. Ademais, o medicamento solicitado pelo impetrante, além de ser de custo elevado, não consta da lista do Programa de Dispensação de Medicamentos em Caráter Excepcional do Ministério da Saúde, certo, ainda, que o mesmo se encontra em fase de estudos e pesquisas. Constato, também, que o estado do Rio Grande do Norte não está se recusando a fornecer tratamento ao impetrante. É que, conforme asseverou em suas razões, "o medicamento requerido é um plus ao tratamento que a parte impetrante já está recebendo" (fl. 14). Finalmente, no presente caso, poderá haver o denominado "efeito multiplicador" (SS 1.836-AgR/RJ, rel.
} 
lista do Programa de Dispensação em Caráter Excepcional do Ministério da Saúde. A ministra enfatizou que o estado do Rio Grande do Norte não estava se negando à prestação dos serviços à saúde e que decisões casuísticas, ao desconsiderarem as políticas públicas definidas pelo Poder Executivo, tendem a desorganizar a atuação administrativa, comprometendo as políticas de saúde ainda incipientes.

O caráter de importância nas ações individuais somente se pode vislumbrar quando se tornam mecanismo de pressão para implementação das políticas públicas, como aconteceu nos casos dos portadores de vírus HIV, ${ }^{16}$ em que o Brasil é um país em que o tratamento é uma referência. Nas primeiras demandas, a contestação do Estado era no sentido de isentar-se de responsabilidade e dizer que se o demandante havia contraído a enfermidade era porque tinha dado causa a isso, numa atitude nitidamente preconceituosa.

O foro adequado é o das ações coletivas, aí se pode discutir o arrolamento de algum outro remédio ou tratamento na lista dos essenciais, veja-se a questão atinente à mudança de sexo. ${ }^{17}$ Houve ajuizamento de ação civil pública pedin-

ministro Carlos Velloso, Plenário, unânime, DJ 11.10.2001), diante da existência de milhares de pessoas em situação potencialmente idêntica àquela do impetrante. Ante o exposto, defiro o pedido para suspender a execução da liminar concedida nos autos do Mandado de Segurança no 2006.006795-0 (fls. 31-35), em trâmite no Tribunal de Justiça do Estado do Rio Grande do Norte.

${ }^{16}$ Em 1991, o Ministério da Saúde dá início à distribuição gratuita de antirretrovirais. A OMS anuncia que 10 milhões de pessoas estão infectadas pelo HIV no mundo. No Brasil, 11.805 casos são notificados. O antirretroviral Videx (ddl) é aprovado nos Estados Unidos e a fita vermelha torna-se o símbolo mundial de luta contra a Aids. A Fiocruz foi convidada pelo Programa Mundial de Aids das Nações Unidas e Organização Mundial da Saúde (Unaids/OMS) para participar da Rede Internacional de Laboratórios para Isolamento e Caracterização do HIV-1. Em 1992, pesquisadores franceses e norte-americanos estabelecem consenso sobre a descoberta conjunta do HIV. A Aids passa a integrar o código internacional de doenças e os procedimentos necessários ao tratamento da infecção são incluídos na tabela do SUS. Combinação entre AZT e Videx inaugura o coquetel antiaids. Disponível em: <www.fiocruz.br/aids20 anos/linha do tempo. Html>. Acesso em: 1o set. 2008

${ }^{17} \mathrm{O}$ início foi uma ação civil pública proposta pelo MPF/ RS, que ocasionou a decisão de 2007 do TRF-4 (Tribunal Regional Federal da 4a Região) em que obrigava o SUS a fazer esse tipo de cirurgia. A decisão do TRF determinava que o governo federal tomasse todas as medidas que possibilitem aos transexuais a realização da cirurgia de mudança de sexo pelo SUS. "Direito Constitucional. Transexualismo. Inclusão na tabela do SUS. Procedimentos médicos de transgenitalização. Princípio da proibição de discriminação por motivo de sexo. Discriminação de gênero. Direitos fundamentais de liberdade, livre desenvolvimento da personalidade, privacidade à dignidade humana e direito à saúde. Força normativa da Constituição."

Rel. Roger Raupp Rios, Processo no 2001.71.00.026279-9., D.E. 22.08.2007. Disponível em: <www.trf4. jus.br/trf4/jurisjud/resultado_pesquisa.phd>. Acesso em: 6 set. 2008. A União recorreu ao STF (Supremo Tribunal Federal), alegando que as operações gratuitas trariam prejuízo aos cofres públicos. Em 12 de dezembro de 2007, a então presidente do STF, ministra Ellen Gracie, suspendeu os efeitos da decisão do TRF-4, em um pedido de suspensão de tutela antecipada. Agora, o próprio Ministério da Saúde decidiu incluir a cirurgia na tabela do SUS. A cirurgia para mudança de sexo fará parte da lista de procedimentos do Sistema Único de Saúde (SUS). A Portaria no 1.707 do Ministério da Saúde, publicada na edição desta terça-feira, no Diário Oficial da União, prevê a realização do processo nos hospitais públicos. A regulamentação dos procedimentos caberá à Secretaria de Atenção à Saúde do Ministério da Saúde. Segundo o texto da portaria publicada nesta terça-feira, a secretaria vai adotar as providências necessárias à estruturação e implantação do processo transexualizador no SUS, definindo os critérios mínimos para o funcionamento, o monitoramento e a avaliação dos serviços. O anúncio de que o SUS 
do a inclusão na tabela do SUS da transgenitalização, que foi julgada procedente. Tal redundou em alteração da posição administrativa, ocasionando a Portaria do Ministério da Saúde no $1.707 / 2008$, que incorpora a alteração de sexo como procedimento oferecido pela rede pública. Três ponderações para que a discussão se trave em âmbito coletivo são apresentadas por Barroso. Primeiro, a discussão no âmbito coletivo exigirá a análise do contexto em que se situam as política públicas; segundo, evita-se a questão da microjustiça, ou seja, a preocupação do juiz com o deslinde daquela ação, esquecendo-se da macrojustiça, atendimento com recursos limitados a demandas ilimitadas; terceiro, a decisão proferida em decisão coletiva terá efeitos erga omnes, preservando a igualdade e a universalidade do atendimento à população.

Assim, a política pública visa à implementação pelo Poder Executivo de um comando constitucional. Especificamente, atinente ao direito à saúde, constata-se que, com o constitucionalismo social inaugurado no Brasil em 1934, o direito à saúde aparece pela primeira vez em sede constitucional. Os textos seguintes se limitaram a atribuir competência à União para planejar sistemas nacionais de saúde, conferindo-lhe a exclusividade da legislação sobre normas gerais de proteção e defesa da saúde, e mantiveram a necessidade de obediência ao princípio que garantia aos trabalhadores assistência médica sanitária.

$\mathrm{Na}$ Constituição atual, o direito à saúde (art. 6º ) é reconhecido como direito social e um dever do Estado (art. 196). A Constituição institui obrigações para todos os entes federados. É competência comum (art. 23, II, CF) à União, aos estados, ao Distrito Federal e aos municípios, competência concorrente sobre a proteção e defesa da saúde, competindo à União o estabelecimento de normas gerais e aos municípios as suplementares (art. 24, §§1ํㅡ e 2ํㅡ, c/c art. 30, II, CF) e cooperação técnica e financeira com o auxílio da União e dos estados (art. 30, VII, CF). Nenhum dos entes federativos está isento de atribuições, isto apresenta dupla crítica no sentido de que todos têm tarefas, mas por outro lado, quando a responsabilidade é tão partilhada entre todos, fica mais difícil cobrar a atribuição de cada um.

O Sistema Único de Saúde (SUS) se propõe a ser uma estrutura descentralizada, com direção única em cada esfera do governo, oferece atendimento integral e

\footnotetext{
faria este tipo de cirurgia foi feito no início de junho, durante a Conferência Nacional de Gays Lésbicas, Bissexuais Travestis e Transexuais, a primeira, no mundo, organizada por um governo federal. Na ocasião, o ministro da Saúde, José Gomes Temporão, lembrou que essa cirurgia é um processo extremamente complexo e delicado, e serão selecionados pouquíssimos centros no Brasil, possivelmente hospitais universitários para o procedimento, que atualmente é feito em hospitais particulares, custa caro e, muitas vezes, envolve riscos para o paciente. O processo cirúrgico transexualizador vai além da cirurgia e envolve uma equipe multidisciplinar composta por psicólogos, assistente social e médicos endocrinologistas, psiquiatras, urologistas e ginecologistas. O ministério promete que todo o atendimento será livre de discriminação. Disponível em: <www.oglobo.globo.com>. Acesso em: 1o set. 2008. Cirurgia para mudança de sexo passa a fazer parte de procedimentos do SUS.
} 
conta com a participação da comunidade (art. 198, CF). Em atenção aos preceitos constitucionais, foram elaboradas as Leis n $\mathrm{os}^{\text {os }}$ 8.080/1990 e 8.142/1990, conhecidas como Lei Orgânica da Saúde (LOS), que são leis nacionais, com caráter de norma geral, que contêm as diretrizes e os limites que devem ser respeitados pela União, pelos estados e pelos municípios ao elaborarem suas próprias normas para garantir o direito à saúde para a população brasileira.

Desse modo, a LOS colabora na definição do direito à saúde, estrutura o SUS, tornando claro seus objetivos e suas atribuições, as diretrizes que devem orientar sua organização, direção e gestão, a forma como estão distribuídas as tarefas entre as três esferas de poder e a forma de participação na comunidade na gestão do sistema em cada uma dessas esferas, além de organizar o seu financiamento, tratando expressamente dos recursos, da gestão financeira, do processo de planejamento e do orçamento, inclusive das transferências intergovernamentais de recursos financeiros.

A questão dos medicamentos, de responsabilidade do SUS, encontra previsão legal na Lei Federal no 8.080/1990, art. 6으, VI, sendo um dos pontos de difícil operacionalização quando se trata da política de Estado para a saúde pública. Desde 1975, ${ }^{18}$ a Organização Mundial da Saúde (OMS) aponta para a necessidade de os estados formularem uma política que permita o acesso e favoreça o uso racional dos medicamentos por todas as pessoas, pois se verificou que o mercado mundial era composto por aproximadamente $70 \%$ de substâncias não essenciais, desnecessárias e até perigosas, e que $1 / 3$ da população não tem acesso a medicamentos essenciais. Para a OMS, a formulação de uma política de medicamentos implica a definição de um conjunto de diretrizes com a finalidade de assegurar para toda a população uma utilização racional dos medicamentos. Isso significa diversos momentos que vão desde a produção até a prescrição dos remédios.

No Brasil, foi editada a Portaria do Ministério da Saúde oㅡ 3.916/1998, ${ }^{19}$ contendo a Política Nacional dos Medicamentos, baseada nas recomendações da OMS, visando fornecer os medicamentos necessários à população mais desprovida de recursos econômicos.

Importante passo para a acessibilidade dos genéricos foi conseguido por meio dos medicamentos genéricos, disciplinados pela Lei ํㅜ 9.787/1999. A partir de então, a Agência Nacional de Vigilância Sanitária (Anvisa) tem estabelecido por meio de resoluções como devem ser feitos o registro, a fabricação, o controle de qualidade e a prescrição dos medicamentos genéricos.

\footnotetext{
${ }^{18}$ Resolução WHA 28.66, da 28a Assembleia Nacional da Saúde.

${ }^{19}$ Publicada no DOU no 215-E, Seção I, de 10 nov. 1998, p. 18-22.
} 


\section{A busca de critérios dentro da escolha adequada constitucionalmente - estudos preliminares}

Feitas as considerações iniciais, no sentido de que é cabível a intervenção judicial dentro da perspectiva da busca da escolha adequada, passa-se à parte mais instigante, que é a busca dos critérios para nortear a interpretação jurisprudencial, em um estudo preliminar.

Primeiro, a formulação de políticas públicas cabe aos poderes Legislativo e Executivo, uma vez que essas opções são uma decorrência da democracia representativa e, por vezes, da participativa. Não cabe aí uma manifestação jurisprudencial, portanto.

Segundo, nos casos de ineficiência ou omissão na execução das políticas públicas, cabe a intervenção judicial. Aí podem aparecer algumas situações.

O Judiciário está autorizado a intervir, quando o poder público não fizer o aporte exigido na Constituição à área da saúde, em conformidade com o art. 198, §2º, da CF.

O foro mais adequado para discutir a inclusão ou a exclusão de algum medicamento é por via das ações coletivas, com legitimados ativos representativos e que permitam um amplo debate a respeito das prioridades, que são estabelecidas a partir das determinações da Organização Mundial da Saúde, levando em conta as peculiaridades de cada país e implementadas pelo ministério respectivo, após debate junto ao Congresso Nacional.

Atinente aos medicamentos em experimentação, que não têm a sua eficácia comprovada, não podem ser objeto de inclusão em lista, pelo Poder Judiciário. Deve-se, ainda, optar pelo genérico de menor custo, quando houver tal possibilidade.

Nos casos de demanda individual, compreende-se a agonia do cidadão que requer o remédio, da família que passa por uma situação difícil e do magistrado que, muitas vezes, se encontra em uma decisão entre a vida e a morte, eminentemente, mas é travado um embate entre as deliberações públicas e privadas e situações de risco em curto e médio prazos.

Por exemplo, às vezes se gasta mais na parte curativa do que preventiva. Vejam-se os números que são investidos em saneamento básico e construção de redes potável, comparativamente à saúde..$^{20}$ Os primeiros são muito tímidos se comparados aos segundos. E a ausência de investimento em saneamento básico é um foco para disseminação de doenças, posteriormente. Então, na premência do momento, descuida-se de uma perspectiva de futuro.

\footnotetext{
${ }^{20}$ No estado do Rio de Janeiro foram gastos com os programas de assistência farmacêutica R \$ 240.621.568, e com o saneamento básico foram investidos R\$102.960.276. Comparando-se as duas quantias, o gasto com saneamento é menos da metade. Disponível em: <www.planejamento.rj.gov.br/orcamentoRJ/2007_ LOA.pdf>. Acesso em: 10 out. 2007.
} 
Assim, a concessão dos medicamentos não deve se pautar por uma abordagem individual dos problemas sociais, mas pela busca de uma gestão eficiente dos escassos recursos públicos, analisando-se os custos e benefícios, desde o prisma das políticas públicas. Aí se pode estabelecer mais uma reflexão a partir do pensamento de Hannah Arendt (2002), quando trata da dicotomia público e privado.

As atividades humanas são condicionadas pelo fato de que os homens vivem juntos. O termo público denota dois fenômenos intimamente correlatos, mas não perfeitamente idênticos. Significa, em primeiro lugar, que tudo o que vem a público pode ser visto e ouvido por todos e tem a maior divulgação possível. Torna-se aparente aquilo que é visualizado e ouvido pelos outros e nós mesmos, constituindo-se na realidade. Segundo, público significa o próprio mundo, na medida em que é comum a todos nós e diferente do lugar que nos cabe dentro dele. Se o mundo deve conter um espaço público, não pode ser construído apenas para uma geração e planejado somente para os que estão vivos: deve transcender a vida de homens mortais.

Dentro dessa perspectiva, as decisões de saúde não devem ser pautadas pelo casuísmo, ou no dizer de Streck (2008:99), de modo solepsista, mas dentro de uma perspectiva de cumprimento do texto constitucional, em busca da resposta adequada dentro dos parâmetros preceituados pela Constituição Federal, sob pena de não haver avanços para as próximas gerações.

\section{Considerações finais}

Na perspectiva de novos temas referentes à administração, o controle judicial das políticas públicas é o tema pautado neste terceiro milênio, que coincide com o processo de redemocratização e reconstitucionalização do país, que é fruto da mudança de paradigma: a busca de efetividade dos direitos fundamentais. Assim, pretende-se contribuir ao debate, a fim de traçar os limites e possibilidades de atuação judicial, no tocante às políticas públicas, e construir um horizonte com perspectiva favorável para milhares de brasileiros que necessitam da eficácia dos direitos fundamentais sociais.

No final do século XX, produziram-se importantes mudanças no âmbito econômico, social e cultural, graças à revolução tecnológica, à globalização, à circulação rápida da informação e das comunicações, aos processos de integração econômica e política, ao término da Guerra Fria, à dissolução da URSS, à queda do muro de Berlim e ao ataque de movimentos fundamentalistas. Todos esses fatores contribuíram para uma mudança no direito administrativo, que até então havia se construído com o aporte iluminista e se estruturado a partir do princípio da legalidade. Com a mudança do aspecto territorial, como um dos elementos do Estado, 
devido à globalização, um novo contexto de Estado vem se definindo, conferindo ao direito administrativo um novo horizonte, como a efetividade das garantias dos cidadãos, que fazem superar a concepção tradicional de busca de equilíbrio das prerrogativas da administração e as garantias dos cidadãos, para almejar o cumprimento do preceituado pela Constituição por parte dos poderes públicos, em especial no que diz respeito aos direitos fundamentais.

O Estado social produziu a superação do conceito de interesse público, calcado exclusivamente a partir dos objetivos da administração e foi substituído pelo interesse coletivo, aberto à participação popular.

Voltando ao pensamento de Hannah Arendt, percebe-se que o direito à saúde está sendo construído por meio das políticas públicas de implementação de tratamentos e de medicamentos ditos essenciais, constituindo-se o Poder Judiciário em um instrumento de realização dos direitos dos cidadãos, desde que se apliquem critérios adequados com os preceitos da Constituição, deixando-se o casuísmo e o subjetivismo nessa seara. Outro importante aspecto a ser considerado quando da implementação das políticas públicas dos direitos sociais que devem atentar aos dispositivos orçamentários. Os últimos 20 anos de constitucionalismo democrático brasileiro demonstram essa busca de efetividade dos direitos fundamentais sociais.

Logo, a crise do direito administrativo é uma mutação para adequar-se às transformações e mudanças sociais vividas no início do século XXI. É necessário voltar-se à pauta dos direitos fundamentais, que até hoje não foram efetivados de maneira universal, considerando, especialmente, o direito à saúde no Brasil. Somente assim poderemos acenar com a construção de um país realmente democrático, com sua população mais saudável nas próximas gerações.

\section{Referências}

ALLI ARANGUREN, Juan-Cruz. Derecho administrativo y globalización. Madrid: Thomson Arandazi, 2004.

ALTHUSSER, Louis. Montesquieu - a política e a história. 2. ed. Lisboa: Editorial Presença, 1972.

ARENDT, Hannah. Los orígenes del totalitarismo. Madrid: Taurus, 1998.

A condição humana. 10. ed. Rio: Forense, 2002.

BARROSO, Luis Roberto. Fundamentos teóricos e filosóficos do novo direito constitucional brasileiro (pós-modernidade, teoria crítica e pós-positivismo). Revista do Ministério Público, Porto Alegre, n. 46, jan./mar. 2002. 
. Da falta de efetividade à judicialização excessiva: direito à saúde, fornecimento gratuito de medicamentos e parâmetros para a atuação judicial. Disponível em: <www.lrbarroso.com.br/pt/noticias.medicamentos.pdf>. Acesso em: 29 ago. 2008. BILBAO UBILLOS, Juan Maria. La eficacia de los derechos fundamentales frente a particulares. Madrid: CEC, 1997.

BUCCI., M. P. D. O conceito de política pública em direito. In: BUCCI, Maria Paula D. (Org.). Política públicas: reflexões sobre o conceito jurídico. São Paulo: Saraiva, 2006.

CADERMATORI, Sergio. Estado de direito e legitimidade: uma abordagem garantista. 2. ed. Campinas: Millennium, 2006.

CANOTILHO, J. J. Gomes; MOREIRA, Vital. Fundamentos da Constituição. Coimbra: Coimbra, 1991.

COUTO e SILVA, Almiro. Apresentação. In: MAURER, Hart. Elementos de direito administrativo alemão. Porto Alegre: Fabris, 2000.

EWALD, François. L'Etat providence. Paris: Bernard Grasset, 1986.

FLEINER, Fritz. Institutionem des Verwaltungsrechts. 8. ed. 1928. In: MIR PUIGELAT. Globalización, Estado y derecho. Las transformaciones recientes del derecho administrativo. Madrid: Civitas, 2004.

GARCÍA DE ENTERRÍA, Eduardo. Las transformaciones de la justicia administrativa: de excepción singular a la plenitud jurisdiccional. ¿Um cambio de paradigma? Pamplona: Thomson Civitas, 2007.

HESSE, Conrado. Significado de los derechos fundamentales. In: BENDA et al. Manual de Derecho Constitucional. Madrid: Instituto Vasco de Administración Pública, 1996.

HOWLETT, Michael; RAMESH, M. Come studiare le poliche pubbliche. Bologna: Il Mulino, 1995. Tradução do original Studying public policy: policy cycles and policy subsystems. Oxford: Oxford University Press, 1995.

KOHN, Jerome (Ed.). Hannah Arendt's centenary: political and philosophic perpectives (part 1). Social Science, v. 74, n. 3, Fall 2007.

KRELL, Andreas J. Direitos sociais e controle judicial no Brasil e na Alemanha: os (des)caminhos de um direito constitucional comparado. Porto Alegre: Fabris, 2002.

LAUBADÈRE, André. Manuel de droi administratif. 15. ed. Paris: L.G.D.J., 1995.

MAURER, Hart. Elementos de direito administrativo alemão. Porto Alegre: Fabris, 2007. 
MOREIRA NETO, Diogo de Figueiredo. Novos horizontes para o direito administrativo: pelo controle das políticas públicas. Revista de Direito do Estado, Rio de Janeiro, n. 4, p. 403-412, out./dez. 2006.

Quatro paradigmas do direito administrativo pós-moderno: legitimidade, finalidade, eficiência, resultados. Belo Horizonte: Fórum, 2008.

MOTESQUIEU, Charles Louis de Secondat. Do espírito das leis. 2. ed. São Paulo: Abril Cultural, 1979.

ORGANIZAÇÃO MUNDIAL DA SAÚDE. Pautas para establecer políticas farmacéuticas nacionales. Genebra: OMS, 1988.

SARLET, Ingo W . A eficácia do direito fundamental à segurança jurídica: dignidade da pessoa humana, direitos fundamentais e proibição de retrocesso social no direito constitucional brasileiro. In: ROCHA, Carmen Lúcia Antunes (Coord.). Constituição e segurança jurídica. Belo Horizonte: Fórum, 2004.

- A eficácia dos direitos fundamentais. 7. ed. Porto Alegre: Livraria do Advogado, 2007.

SCLIAR, Moacyr. Do mágico ao social: trajetória da saúde pública. São Paulo: Senac, 2002.

SIGMANN, Jean. 1848 - Las revoluciones románticas y democráticas de Europa. 3. ed. Madrid: Siglo Veintiuno Editorial, 1985.

SOCIEDADE BRASILEIRA DE VIGILÂNCIA DE MEDICAMENTOS (SOBRAVIME). O que é o uso racional de medicamentos. São Paulo: Sobravime, 2001.

STRECK, Lênio. Jurisdição constitucional e hermenêutica: uma nova crítica do direito. 2. ed. Rio de Janeiro: Forense, 2004.

Decisionismo e discricionariedade judicial em tempos pós-positivistas: o solipsismo hermenêutico e os obstáculos à concretização da Constituição no Brasil. Separata: o Direito e o Futuro do Direito. Almedina: Coimbra, 2008.

SZWARCWALD, Célia L. Mortalidade infantil no Brasil: Belíndia ou Bulgária? Cadernos de Saúde Pública, v. 13, n. 3, Rio de Janeiro, 1997. Disponível em: <www. saelosp.org>. Acesso em: 8 mar. 2009.

WALINE, Marcel. Traité élémentaire de droit administratif. 6. ed. Paris: Recueil Sirey, 1952. 